\title{
PENINGKATAN KEMAMPUAN PENALARAN MATEMATIS MAHASISWA CALON GURU MATEMATIKA MELALUI BLENDED- LEARNING DENGAN STRATEGI PROBING-PROMPTING
}

\author{
Dahlia Fisher \\ Universitas Pasundan \\ dahliafisherpmat@unpas.ac.id
}

\begin{abstract}
Abstrak
Blended learning adalah metode belajar yang menggabungkan dua atau lebih metode pembelajaran. Tujuan yang ingin dicapai dalam penelitian ini adalah untuk mengetahui peningkatan kemampuan penalaran matematis mahasiswa calon guru matematika, melalui Blended Learning dengan strategi pembelajaran Probingprompting. Metode penelitian yang digunakan adalah metode penelitian kuantitatif, dengan membagi objek penelitian menjadi dua kelompok. Kelompok pertama adalah kelompok kelas eksperimen yaitu kelompok mahasiswa calon guru yang mendapatkan Blended Learning dengan Strategi Probing-Prompting dan kelompok kedua adalah kelompok kontrol; yaitu mahasiswa calon guru yang mendapatkan pembelajaran konvensional. Penelitian dilakukan terhadap mahasiswa calon guru semester 6 dari salah satu universitas di Bandung, Jawa Barat. Berdasarkan penelitian ini, diketahui bahwa: kelompok kelas eksperimen; yaitu kelompok mahasiswa calon guru yang mendapatkan Blended Learning memiliki peningkatan kemampuan penalaran matematis yang lebih baik dibandingkan dengan kelompok kelas kontrol. Hal tersebut dapat terlihat dari hasil perhitungan gain ternormalisasi kelas eksperimen mencapai rata-rata 0,50 sementara gain ternormalisasi kelas kontrol mencapai rata-rata 0,34. Meskipun keduanya masih dalam kategori sedang, namun berdasarkan hasil uji-t dua pihak didapatkan bahwa dalam peningkatan tersebut terdapat perbedaan yang signifikan.
\end{abstract}

Kata Kunci: Blended-Learning, Probing-Prompting, dan Penalaran Matematis.

\begin{abstract}
Blended learning is a learning method that combines two or more learning method. The objective of this research is to know the improvement of mathematical reasoning ability of student of mathematics prospective teacher, through Blended Learning with Probing-prompting learning strategy. The research method used is quantitative research, and divides participants into two groups. The first group is the experimental class group, it is the group of prospective teachers who get Blended Learning with Probing-Prompting Strategy and the second group is the control group; which is prospective teachers who get conventional learning. The study was conducted on 6th semester prospective teacher students from one university in Bandung, West Java, Indonesia. Based on this research, it is known that: experimental class group; which is the group of prospective teachers who get Blended Learning has improved the ability of mathematical reasoning is better than the control class group. It can be seen from the results of the normalized gain calculation of the experimental class reaches an average of 0.50 while the normalized gain of the control class reaches an average of 0.34 . Although both are still in medium category, but based on t-test results between two parties, found that the increase has significant differences.
\end{abstract}

Keywords: Blended-Learning, Probing-Prompting, dan Mathematical Reasoning.

\section{PENDAHULUAN}

Penalaran dalam matematika merupakan sesuatu yang pokok dan penting, tidak pernah sedikitpun penalaran lepas dari matematika, sehingga dapat dikatakan bahwa penalaran adalah intinya matematika. Setiap belajar matematika pasti berkenaan dengan penalaran, oleh karenanya kemampuan penalaran akan menggambarkan kemampuan matematiknya. Untuk mewujudkan hal tersebut, pada Kurikulum 2004 telah dirumuskan lima kecakapan atau kemahiran yang diharapkan dapat dicapai dalam belajar matematika, yaitu: (1) belajar untuk berkomunikasi (mathematical communication); (2) belajar untuk bernalar (mathematical reasoning); (3) belajar untuk memecahkan masalah (mathematical problem solving); (4) belajar untuk mengaitkan ide (mathematical connections); dan (5) pembentukan sifat positif terhadap matematika (positive attitudestowards mathematics). Kelima hal tersebut dikenal dengan daya matematika (mathematical power). 
Di sisi lain upaya peningkatan kualitas pembelajaran matematika perlu mempertimbangkan perubahan-perubahan dalam proses pembelajaran, yang antara lain ditandai dengan adanya perubahan dari model belajar terpusat pada guru ke model terpusat pada peserta didik, dari kerja terisolasi ke kerja kolaborasi, dari pengiriman informasi sepihak ke pertukaran informasi, dari pembelajaran pasif ke pembelajaran aktif dan partisipatif, dari yang bersifat faktual ke cara berpikir kritis, dari respon reaktif ke proaktif, dari konteks artificial ke konteks dunia nyata, dari single media ke multimedia. Oleh karena itu, pembelajaran harus berpotensi mengembangkan suasana belajar mandiri. Dalam hal ini, pembelajaran dituntut dapat menarik perhatian peserta didik dan sebanyak mungkin memanfaatkan momentum kemajuan teknologi khususnya dengan mengoptimalkan pemanfaatan teknologi informasi dan komunikasi.

Walaupun infrastruktur TIK di Indonesia masih kalah dari beberapa Negara di luar negeri, sebaiknya para insan pendidikan, khususnya para tenaga pengajar dan pengelola lembaga pendidikan, harus mulai berpikir dan bertindak untuk memajukan e-learning. Jika tidak segera bertindak, dimungkinkan sekolah-sekolah di Indonesia akan kehilangan para peserta didiknya, yang lebih suka mengikuti program distance learning dari sekolah-sekolah di luar negeri. Di samping itu, UNESCO juga telah menetapkan standar bagi guru untuk dapat menggunakan TIK bagi keperluan pembelajarannya (Majumdar, 2005). Pemerintah Indonesia melalui Keppres No. 6/2001 telah mulai mencanangkan eeducation. Ini berarti bahwa pemerintah telah melakukan inisiasi pemanfaatan TIK dalam bidang pendidikan. Untuk mendukung pelaksanaan Keppres tersebut, Direktorat Jenderal Pendidikan Tinggi Depdiknas memfasilitasi pengembangan infrastruktur TIK dan jaringannya bagi lembaga pendidikan tinggi di Indonesia. Hal ini dimaksudkan untuk meningkatkan literasi komputer (computer literacy / Jw : "melek komputer") bagi dosen dan mahasiswa berturut-turut 80\% dan $50 \%$ pada tahun 2009. Oleh karena itu, TIK bagi guru adalah kunci utama dalam meningkatkan kualitas pendidikan dan relevansi.. Oleh karena itu, muncul istilah-istilah seperti e-teacher, e-test, e-library, e-assignment, eeducation, virtual school, virtual university, e-learning, dan sebagainya. e-learning adalah pembelajaran yang menggunakan TIK untuk mentransformasikan proses pembelajaran antara pendidik dan peserta didik. Tujuan utama penggunaan teknologi ini adalah meningkatkan efisiensi dan efektivitas, transparansi, dan akuntabilitas pembelajaran. TIK yang digunakan untuk menyampaikan materi pembelajaran dalam elearning ini dapat berupa komputer, LAN (local area network), WAN (wide area network), internet, intranet, satelit, TV, CD ROM, dan sebagainya. Proses pembelajaran dapat disampaikan secara synchronously (pada waktu bersamaan) atau asynchronously (pada waktu yang berbeda). Bahan pembelajaran yang bercirikan multimedia, mempunyai teks, grafik, animasi, simulasi, audio, video. Hal ini merupakan kelebihan yang dimiliki media berbasis komputer. Di samping itu, suatu e-learning juga harus mempunyai kemudahan bantuan profesional isi pelajaran secara on line.

Pada era sekarang, ilmu pengetahuan telah berkembang pesat di mana pada abad ini teknologi utama yang menjadi landasannya adalah komputer melalui jaringan internet. Internet dijadikan salah satu sumber belajar tanpa batas ruang dan waktu Menurut Clark (dalam Hasbullah, 2014) terdapat lima fungsi pemanfaatan internet sebagai sumber belajar yakni: (a) media as technology, (b) media as tutor or teacher, (c) media as socializing agents, (d) media as motivators for learning, dan (e) media as problem solving". Salah satu strategi yang dapat meningkatkan proses berpikir dengan memberikan pertanyaanpertanyaan adalah probing-prompting. Suherman (2008), strategi probing-prompting adalah strategi pembelajaran dengan cara dosen menyajikan serangkaian pertanyaan yang sifatnya menuntun dan menggali sehingga terjadi proses berpikir dan bernalar. 
Menurut Yaniawati (2005) beberapa perpendidikan tinggi di negara-negara maju memberikan beberapa alternatif model kegiatan pembelajaran/perkuliahan kepada para peserta didiknya. Tujuannya agar para peserta didik dapat secara fleksibel mengelola kegiatan perkuliahannya sesuai dengan waktu dan aktivitas sehari-hari peserta didik. Ada tiga alternatif model kegiatan pembelajaran yang dapat dipilih peserta didik, yaitu: 1) sepenuhnya secara tatap muka (konvensional) 2) sebagian secara tatap muka dan sebagian lagi melalui internet, atau 3) sepenuhnya melalui internet. Dari hasil penelitian Yaniawati (2005), terdapat perbedaan yang signifikan daya matematik antara mahasiswa calon guru yang belajarnya melalui full e-learning, blended-learning, dan pembelajaran konvensional. Daya matematik mahasiswa yang melalui blended learning lebih baik dibandingkan melalui pembelajaran lainnya (full e-learning dan konvensional), berdasarkan latar belakang masalah di atas, peneliti tertarik untuk meneliti Peningkatan Kemampuan Penalaran Matematis Mahasiswa Calon Guru Matematika melalui Blended Learning Dengan Strategi Probing-Prompting.

\section{METODE}

Penelitian ini menggunakan metode campuran (mixed methods), yaitu metode penelitian yang menggabungkan atau menghubungkan metode penelitian kuantitatif dan kualitatif (Creswell, 2009). Pemilihan jenis penelitian kuantitatif dan kualitatif atau mixed methods adalah untuk mendapatkan fakta yang lebih komprehensif tentang kemampuan penalaran matematis belajar mahasiswa calon guru matematika melalui blended learning dengan strategi probing prompting.

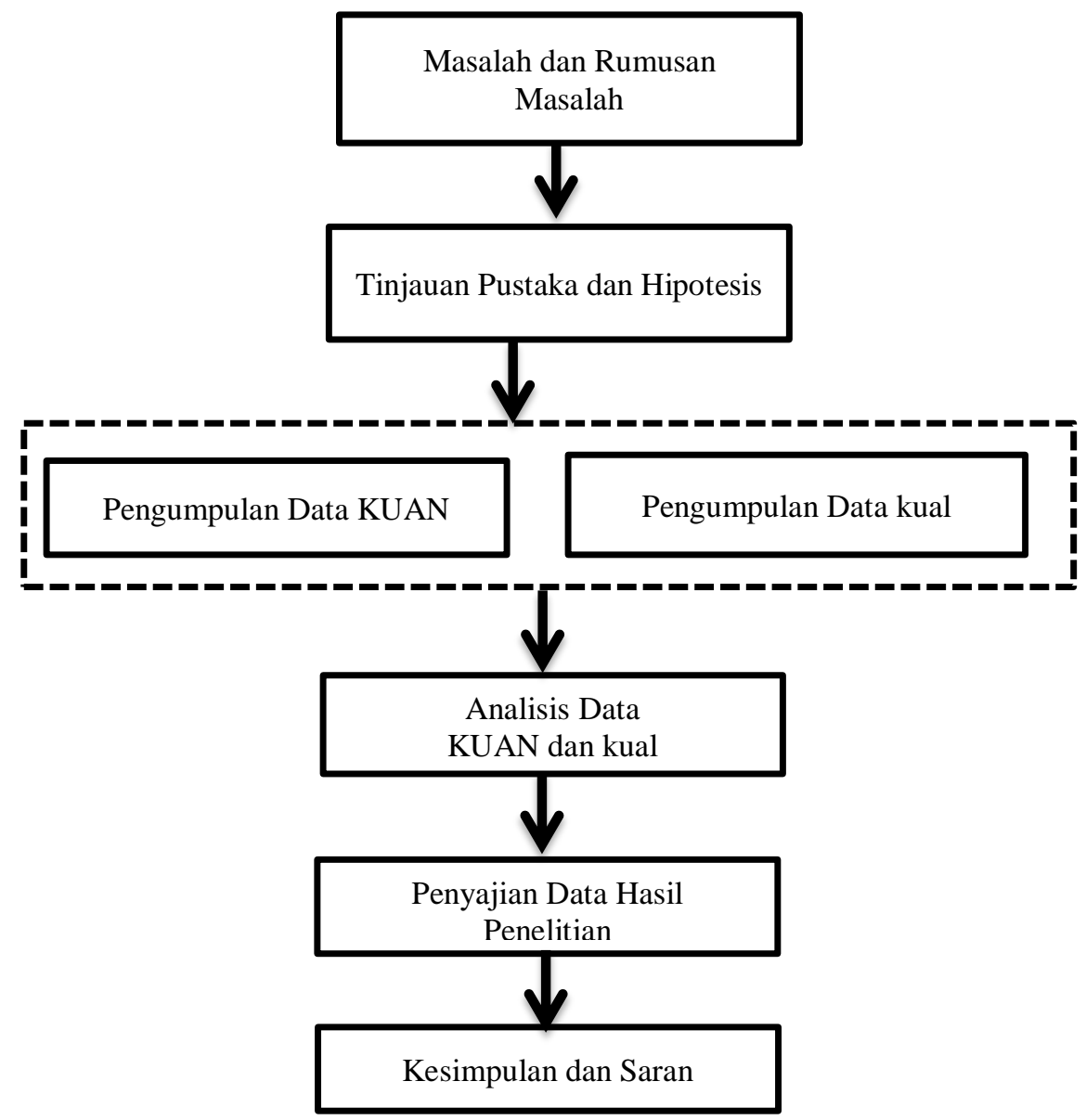

Gambar 2. Langkah-langkah Metode Embedded Design 
Instrumen penelitian yang disusun terdiri dari: (1) tes kemampuan awal mahasiswa dan tes kemampuan penalaran matematis; (2) angket untuk mengukur kemampuan penalaran mahasiswa;(3) lembar observasi untuk mencatat aktivitas dosen dan mahasiswa ketika pembelajaran; (4) panduan wawancara untuk mengetahui kesulitan mahasiswa yang tidak dapat diketahui dari lembar jawaban mahasiswa. Langkah-langkah penelitian metode Embedded Design yang dilakukan diperlihatkan pada Gambar 2 diatas.

Populasi dalam penelitian ini adalah mahasiswa S1 Pendidikan Matematika, FKIP, UNPAS. Sedangkan sampel dalam penelitian ini adalah 80 orang mahasiswa yang dipilih secara acak kelas. Teknik pengumpulan data yang digunakan dalam penelitian ini meliputi teknik pengumpulan data kuantitatif dan kualitatif. Pengumpulan data kuantitatif dan kualitatif dilakukan pada waktu yang bersamaan dan bergantian dalam selang waktu yang tidak terlalu lama. Sementara itu, untuk mengukur keberhasilan pembelajaran, kepada subjek penelitian diberikan dua kali tes kemampuan yang sama, yaitu dia awal (pretest) dan di akhir semester (posttest). Skor peningkatan kemampuan penalaran matematis belajar mahasiswa diperoleh dengan mengurangkan skor posttest dengan skor pretest.

Selain itu, data kualitatif dilakukan untuk melengkapi data kuantitatif agar analisis hasil penelitian yang dilakukan menjadi lebih luas, mendalam, dan bermakna. Data kualitatif diperoleh melalui instrument lembar observasi, video rekaman, catatan lapangan, serta wawancara dengan subjek penelitian. Langkah-langkah analisis data dipisahkan berdasarkan jenis data tersebut. Data kuantitatif diperoleh dari analisis pretest dan posttest, sedangkan data kualitatif diperoleh dari analisis lembar observasi, wawancara, angket, serta catatan lapangan dan dokumentasi.

Peralatan yang digunakan dalam penelitian ini tidak ada yang khusus, hanya berupa koneksi internet untuk kelas Blended Learning Probing-prompting (BLPP). Mahasiswa dapat menggunakan modem sendiri atau dapat memanfaatkan fasilitas WiFi yang ada di kampus. Website yang digunakan untuk kelas BLPP menggunakan media pembelajaran yang tersedia secara gratis yaitu Edmodo (http://www.edmodo.com). Contoh Platform Edmodo adalah sebagai berikut.

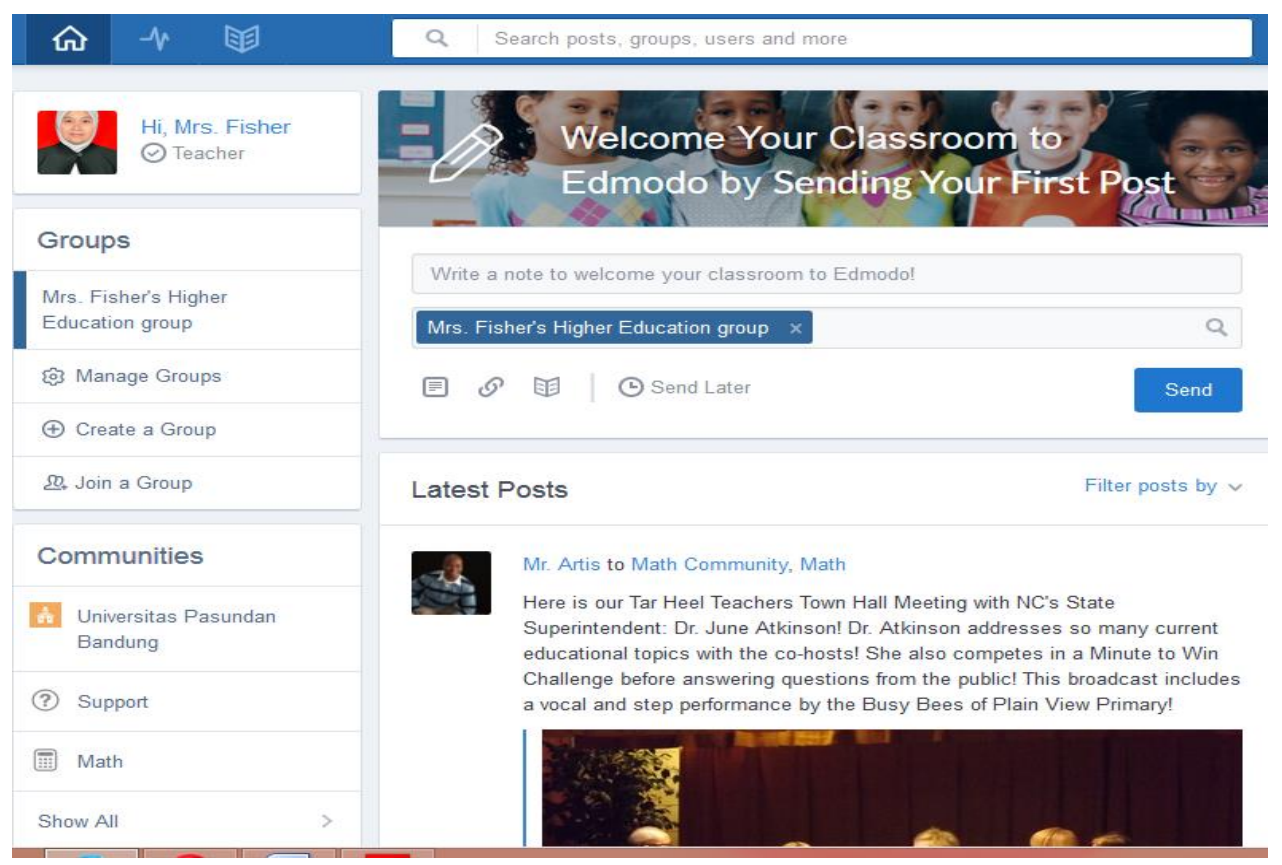

Gambar 3. Contoh Platform Edmodo 


\section{HASIL DAN PEMBAHASAN}

Analisis data yang dilakukan terhadap hasil penelitian ini adalah analisis terhadap data hasil tes awal, tes akhir, dan skala sikap. Tes awal digunakan untuk mengetahui kemampuan penalaran matematika mahasiswa, sedangkan analisis presepsi digunakan untuk mengetahui presepsi mahasiswa mahasiswa terhadap pembelajaran blended learning. Adapun pengolahan data dapat dilakukan dengan menggunakan SPSS versi 17.0 for windows.

\section{Analisis Data Tes Awal (Pretes)}

Data tes awal diperoleh dari hasil tes awal yang telah diberikan sebelum pembelajaran. Analisis data tes awal pada kelompok eksperimen dan kelompok kontrol dapat dilihat pada Tabel 1 berikut:

\section{Tabel 1}

Nilai Maksimum, Nilai Minimum, Rata-rata dan Simpangan Baku Tes Awal Kelas Eksperimen dan Kelas Kontrol

\begin{tabular}{cccccc}
\hline \multirow{2}{*}{ Kelas } & \multicolumn{5}{c}{ Tes Awal (Pretes) } \\
& N & $\begin{array}{c}\text { Nilai } \\
\text { Maksimum }\end{array}$ & $\begin{array}{c}\text { Nilai } \\
\text { Minimum }\end{array}$ & $\begin{array}{c}\text { Rata- } \\
\text { Rata }\end{array}$ & $\begin{array}{c}\text { Simpangan } \\
\text { Baku }\end{array}$ \\
\hline Ekperimen & 39 & 6 & 0 & 2.69 & 1.575 \\
Kontrol & 37 & 6 & 0 & 3.11 & 1.577 \\
\hline *Data selengkapnya dapat dilihat pada Lampiran &
\end{tabular}

Kedua kelas tersebut berdistribusi normal dan memiliki variansi yang homogen, selanjutya dilkukan uji kesamaan dua rerata dengan uji-t melalui aplikasi program SPSS 17.0 for windows menggunakan Independent Sample t-tes dengan asumsi kedua varians homogen (equal varians assumed) dengan taraf signifikansinya 0.05 .

Setelah dilakukan pengolahan untuk tes awal, tampilan output SPSS dapat dilihat seperti terdapat pada Tabel 2 berikut ini :

\section{Tabel 2}

\section{Output Uji-t Tes Awal (Pretes) Kelas Eksperimen dan Kelas Kontrol}

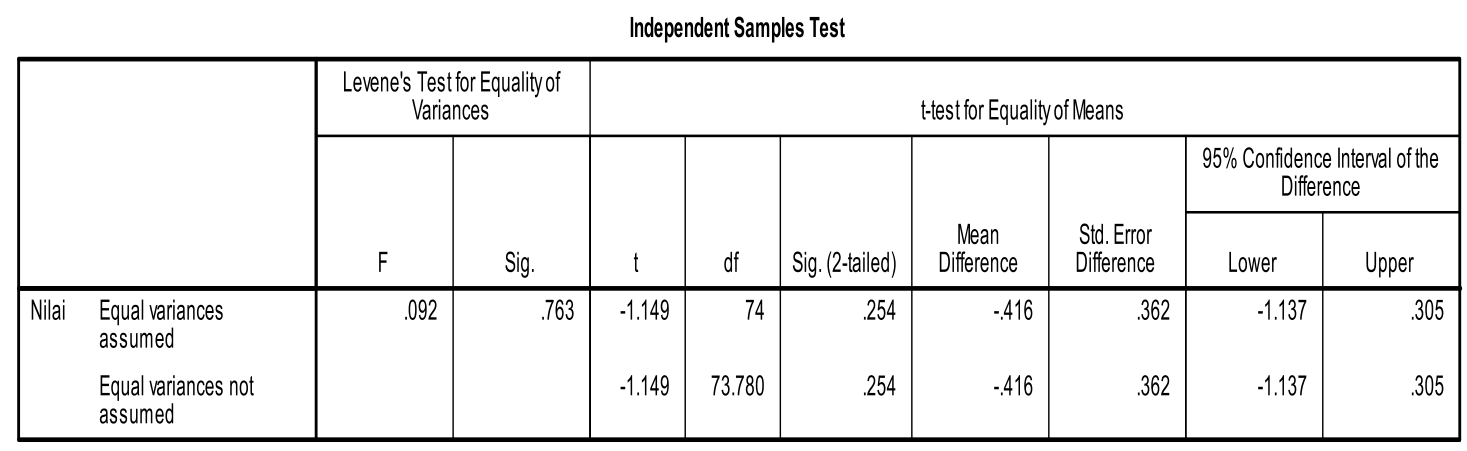

Pada Tabel 2 di atas, terlihat bahwa nilai signifikansi pada signifikansi (2-tailed) adalah 0,254. Oleh karena nilai signifikansi > 0,05, maka Ho diterima atau tidak terdapat perbedaan yang signifikan kemampuan penalaran matematis mahasiswa yang memperoleh pembelajaran blended learning dengan strategi probing prompting dan kemampuan penalaran matematis mahamahasiswa yang memperoleh pembelajaran dengan strategi probing prompting. 


\section{Analisis data Tes Akhir (Postes)}

Data tes akhir diperoleh dari hasil tes akhir yang telah diberikan sebelum pembelajaran. Analisis data tes akhir pada kelompok eksperimen dan kelompok kontrol dapat dilihat pada Tabel 3 berikut.

\section{Tabel 3}

Nilai Maksimum, Nilai Minimum, Rata-rata dan Simpangan Baku Tes AkhirKelas Eksperimen dan Kelas Kontrol

\begin{tabular}{cccccc}
\hline Kelas & \multicolumn{4}{c}{ Tes Akhir (Postes) } \\
& N & $\begin{array}{c}\text { Nilai } \\
\text { Maksimum }\end{array}$ & $\begin{array}{c}\text { Nilai } \\
\text { Minimum }\end{array}$ & $\begin{array}{c}\text { Rata- } \\
\text { Rata }\end{array}$ & $\begin{array}{c}\text { Simpangan } \\
\text { Baku }\end{array}$ \\
\hline Ekperimen & 39 & 15 & 3 & 8.56 & 3.48 \\
Kontrol & 37 & 13 & 2 & 7.00 & 2.51 \\
\hline
\end{tabular}

Setelah dilakukan pengolahan untuk tes akhir, data tersebut berdistribusi normal dan homogen, sehingga untuk uji perbandingan rata-rata nya dapat dilakukan dengan Uji-t. Tampilan output SPSS dapat dilihat seperti terdapat pada Tabel 4.

Pada Tabel 4, terlihat bahwa nilai signifikansi pada signifikansi (2-tailed) adalah 0,028 . Oleh karena nilai signifikansi $<0,05$, maka Ho ditolak atau terdapat perbedaan yang signifikan kemampuan penalaran matematis mahasiswa yang memperoleh pembelajaran blended learning dengan strategi probing prompting dan kemampuan penalaran matematis mahamahasiswa yang tidak memperoleh pembelajaran blended learning dengan strategi probing prompting.

\section{Tabel 4}

Output Uji-t Tes Akhir (Postes) Kelas Eksperimen dan Kelas Kontrol

Independent Samples Test

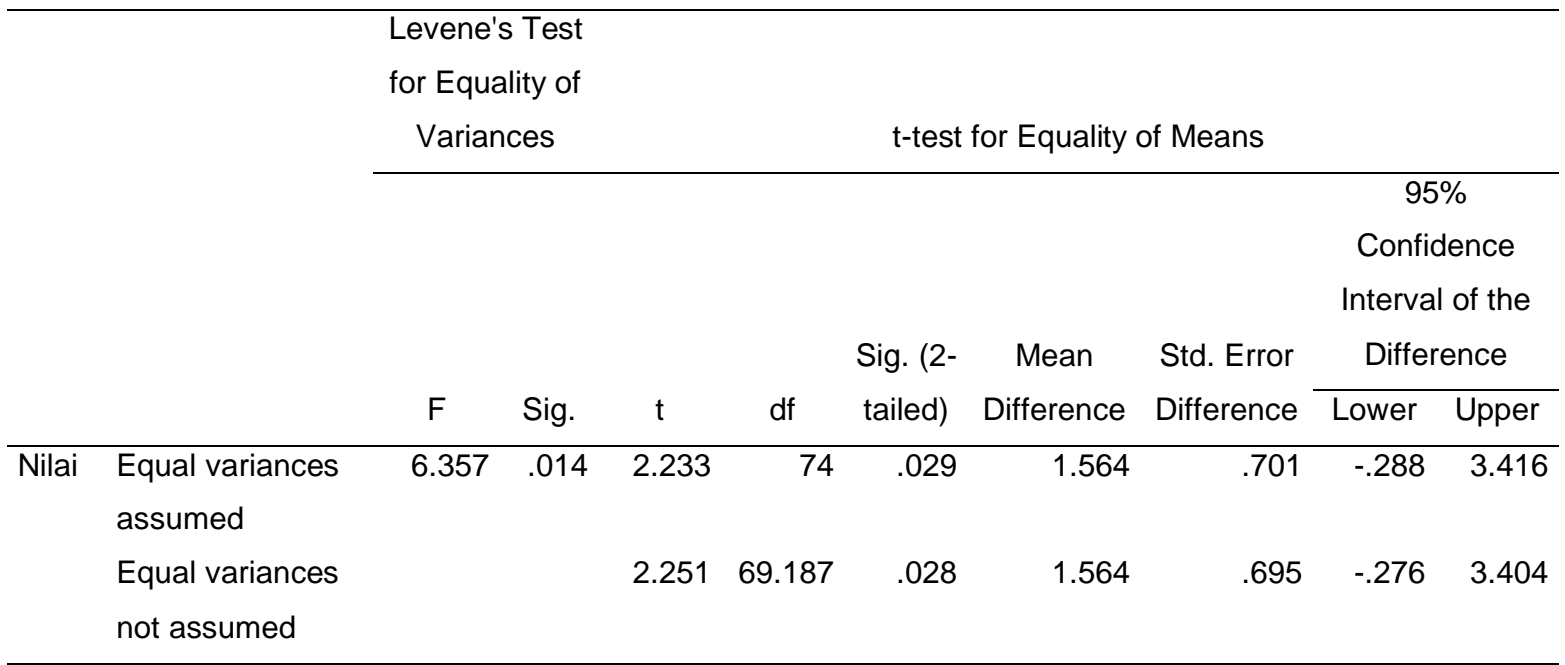




\section{Skor Gain}

Untuk melihat peningkatan dari pretes ke postes, maka dilakukan perhitungan peningkatannya (gain). Gain terdiri dari absolute gain atau actual gain (gain mutlak atau gain actual) dan normalized gain (gain ternormalisasi). Gain mutlak adalah besarnya peningkatan skor dari pretes ke postes. Jadi gain mutlak sama dengan skor postes dikurangi dengan skor pretes. gain ternormalisasi adalah proporsi gain mutlak terhadap gain maksimal yang dapat dicapai.

Untuk melihat penigkatan kemampuan penalaran Matematis siswa yang memperoleh pembelajaran blended learning dengan strategi probing prompting dan siswa yang memperoleh pembelajaran konvensional adalah dengan menghitung gain kedua kelompok dengan menggunakan rumus gain ternormalisasi. Hasi perhitungan gain ternormalisasi selengkapnya disajikan pada Tabel 5 berikut.

Tabel 5

Gain Ternormalisasi Kelas Eksperimen dan Kelas Kontrol

\begin{tabular}{lcccl}
\hline \multicolumn{1}{c}{ Aspek } & \multicolumn{2}{c}{ Eksperimen } & \multicolumn{2}{c}{ Kontrol } \\
& $\begin{array}{c}\text { Rata-rata gain } \\
\text { ternormalisai }\end{array}$ & Kategori & $\begin{array}{c}\text { Rata-rata gain } \\
\text { ternormalisai }\end{array}$ & Kategori \\
\hline $\begin{array}{l}\text { Kemampuan } \\
\begin{array}{l}\text { Penalaran } \\
\text { Matematis }\end{array}\end{array}$ & 0,50 & Sedang & 0,34 & Sedang \\
\hline
\end{tabular}

Dari Tabel 5 terlihat bahwa rata-rata gain ternormalisasi kemampuan penalaran Matematis siswa kelas eksperimen lebih besar daripada kelas kontrol. Meskipun kedua kategori gain interpretasinya sedang. Sementara untuk uji eprbedaan rata-rata, terlebih dahulu dilakukan uji normalitas. Setelah diuji normalitas didapatkan bahwa data gain ternormalisasi tidak berdistribusi normal, sehingga untuk pengujian perbadaan rata-ratanya dilakukan dengan Uji Mann-Whitney. Hasil uji perbedaan rata-rata skor gain ternormalisasi dapat dilihat pada Tabel 6.

Tabel 6

Deskripsi Uji Mann Whitney Perbedaan Rata-Rata Skor Gain Ternormalisasi

\begin{tabular}{|c|c|c|c|c|}
\hline \multicolumn{5}{|c|}{ Ranks } \\
\hline & Kelompok & & & Sum of \\
\hline & & $\mathbf{N}$ & Mean Rank & Ranks \\
\hline \multirow[t]{3}{*}{ Nilai } & Eksperimen & 39 & 45.77 & 1785.00 \\
\hline & Kontrol & 37 & 30.84 & 1141.00 \\
\hline & Total & 76 & & \\
\hline
\end{tabular}

Tabel 7

Hasil Uji Mann Whitney Perbedaan Rata-Rata Skor Gain Ternormalisasi

\begin{tabular}{lr}
\multicolumn{2}{c}{ Test Statisticsa } \\
\hline \multicolumn{2}{c}{ Nilai } \\
\hline Mann-Whitney U & 438.000 \\
Wilcoxon W & 1141.000 \\
Z & -2.951 \\
Asymp. Sig. (2-tailed) & .003 \\
a. Grouping Variable: Kelompok \\
\hline
\end{tabular}


Berdasarkan Tabel 7. diketahui nilai statistik uji Z yaitu -4.951 dan nilai Asymp. Sig. ( 2 tailed) $0.003<0,05$. Hasil uji statistik menolak $\mathrm{H}_{0}$. Artinya terdapat perbedaan yang signifikan rata-rata nilai gain ternormalisasi kemampuan penalaran Matematis kelas eksperimen dan kelas kontrol secara keseluruhan.

\section{Persepsi Mahasiswa terhadap Implementasi e-learning dan Blended Learning}

Pada bagian pertama materi wawancara (A) meliputi pertanyaan mengenai pengenalan, kemampuan dan kebiasaan responden menggunakan komputer, penggunaan software dan jaringan. Hasil penelitian menunjukkan bahwa semua responden ( 80 dari 80 responden) pengguna Microsoft office. Hal ini sesuai dengan penggunaan untuk belajar (89\%) dalam arti mengerjakan tugas-tugas kuliah. Sebagian menggunakan aplikasi web browser (65\%) untuk kegiatan belajar, chatting dan komunikasi lainnya.

Pada penelitian tentang lama penggunaan komputer, sebanyak 59\% responden menggunakan komputernya lebih dari 3 jam per hari. Sisanya $26 \%$ mengunakan lebih dari 2 jam per hari, sisanya $15 \%$ menggunakan komputer kurang dari 2 jam per hari.

Dalam hal penggunaan internet, sebagian besar mahasiswa (91\% dari responden) menyatakan bahwa mereka menggunakan komputer untuk belajar, searching bahan ajar di internet, membuat paper dan bahan presentasi dengan power point, $91 \%$ mahasiswa menggunakan internet untuk berkomunikasi lewat e-mail, chatting, facebook, dan lainnya. $45 \%$ untuk kepentingan rekreasi (seperti melihat film di you tube atau melakukan game online dan sebagainya).

Pertanyaan mengenai pengenalan aplikasi e-learning menunjukkan, sebanyak 69\% responden menyatakan tahu tentang e-learning, $31 \%$ responden mahasiswa menyatakan tidak mengenal.

Presepsi mahasiswa mengenai kesiapan penggunaan e-learning dengan platform edmodo di kelas pada saat pembelajaran, 66 responden menjawab mungkin bisa menggunakan aplikasi elearning, 6 orang ragu-ragu dan 8 orang tidak menjawab.

Kurangnya pengenalan akan program e-learning yang digunakan menyebabkan mahasiswa tidak mampu menetapkan presepsi yang tepat mengenai penilaian dengan proses pembelajaran lewat e-learning menunjukkan perlu sosialisasi dan pembuktian bahwa penilaian lewat e-learning dapat lebih adil dan mudah diperoleh.

\section{SIMPULAN} berikut:

Dari hasil penelitian ada beberapa hal yang dapat disimpulkan, diantaranya adalah sebagai

1. Model Blended Learning dengan strategi Probing-Prompting memberikan pengaruh yang signifikan terhadap peningkatan kemampuan Penalaran Matematis Mahasiswa Calon Guru.

2. Mahasiswa Calon Guru yang belajar dengan model Blended Learning dengan strategi ProbingPrompting memiliki kenaikan kemampuan Penalaran Matematis yang lebih baik dalam mata kuliah Analisis Real, jika dibandingkan dengan Mahasiswa Calon Guru yang belajar dengan model pembelajaran konvensional.

\section{DAFTAR PUSTAKA}

Arikunto, S. (2001). Prosedur Penelitian Suatu Pendekatan Praktek. Jakarta: Bumi Aksara

Creswell, John W. (2010). Research Design Pendekatan Kualitatif, Kuantitatif, dan Mixed. Jogjakarta : Pustaka Pelajar.

Curtis J.Bonk, Charles R. Graham. (2006). The Handbook of Blended learning. USA : Pfeiffer.

Depdiknas. (2003). Undang-undang Nomor 20 Tahun 2003 tentangSistem Pendidikan Nasional.

Driscoll, M. (2002). Blended Learning: Let's Get Beyond the Hype. [online].

Diakses https://www-07.ibm.com/services/pdf/blended_learning.pdf

Elliott, M. (2002). Blended Learning: The Magic Is In The Mix. In A. Rossett (Ed.), The ASTD elearning handbook (pp. 58-63). New York : McGraw-Hill. 
Ernst, J.V. (2008). “A Comparison of Traditional and Hybrid Online Instructional Presentation in Communication Technology. Journal of Technology Education Vol. 19 No. 2, halaman 4049. http://scholar. lib.vt.edu/ejournals/JTE/v19n2/pdf/ernst.pdf. Diakses 24 April 2016.

Garnham, C. dan Kaleta, R. (2002). "Introduction to Hybrid Course". Teaching with Technology Today, Volume 8, Number 6: March 20, 2002. http://www.wisconsin.edu/ttt/articles/garnham. Diakses 24 April 2016

Hapizah, (2015). Peningkatan Kemampuan Penalaran Matematis, Komunikasi Matematis, dan Kemandirian Belajar Mahasiswa Calon Guru Matematika Melalui Blended Learning dengan Strategi Probing-prompting. (Disertasi). Sekolah Pasca Sarjana Universitas Pendidikan Indonesia, Bandung.

Hasbullah.(2008). "Perancangan dan Implementasi Model Pembelajaran E-learning Untuk Meningkatkan Kualitas Pembelajaran di JPTE FPTK UPI," Jurnal Pendidikan. Bandung: Universitas Pendidikan Indonesia.

Hicks, M., dkk. (2001). Enhancing online teaching: Designing responsive learning environments. The International Journal for Academic Development. 6(2),hlm. 143-151

Indrawan, R. dan Yaniawati, P. (2016). Metodologi Penelitian Kuantitatif, kualitatif, dan Campuran untuk Manajemen, Pembangunan dan Pendidikan. Refika Aditama, Bandung.

Kurtus, R. (2004). Blended Learning. Available at http://www.school-for champions.com/elearning /blended.htm [diakses 16-03-2016]

Prayitno, W. (2015). Penerapan Blended Learning Dalam Pengembangan Pendidikan Dan Pelatihan (Diklat) Bagi Pendidik Dan Tenaga Kependidikan (PTK). http://lpmpjogja.org/wpcontent/uploads/2015/08/Artikel-br_10juli-Penerapan-Blended-Learning-dalamPengembangan-Diklat-PTK_Wendhie.pdf.Diakses 24 April 2016.

Russefendi, H.E. T. (1998). Dasar-dasar Penelitian Pendidikan dan Bidang Non-Eksakta lainnya. Semarang: IKIP Semarang Press.

Suherman, E. dkk. (2001). Strategi Pembelajaran Matematika Kontemporer. Bandung: JICA

Tamalene, Hanisa. (2010). Pembelajaran Matematika dengan Model CORE melalui Pendekatan Keterampilan Metakognitif untuk Meningkatkan Kemampuan Penalaran Matematis Siswa Sekolah Menengah Pertama. Tesis Magister pada PPS UPI bandung: Tidak diterbitkan.

Yaniawati, P. (2010). E-learning Alternative Pembelajaran Kontemporer. Bandung: Arfino Raya.

Yaniawati, P. (2014). Budaya Belajar Mandiri Mahasiswa Melalui Pemanfaatan E-Learning dalam Pembelajaran Matematika. Bandung: Universitas Pasundan.

Yaniawati, P. (2012). Pengaruh E-Lerning untuk meningkatkan Daya Matematik Mahasiswa. Cakrawala Pendidikan Jurnal Ilmiah Pendidikan. November 2012, Th. XXXI, No. 3. Halaman 381-393. 